\title{
Using of animal models of angiogenesis to confirm a Bidens pilosa-sourced polyacetylenic glucoside inhibits angiogenesis targeting hypoxia through VEGF and PDIA4 suppression
}

Cheng-Ying Yang ${ }^{1}$, Jhih-Ying Wong ${ }^{1}$, Chuen-Fu Lin ${ }^{2}$, Chih-Yu Chang ${ }^{1}$, and Cicero Lee-Tian Chang ${ }^{1 *}$

1 Department of Veterinary Medicine, College of Veterinary Medicine, National Chung Hsing University, 40227 Taichung, Taiwan; mitisoishen@gmail.com (C.Y.Y.); a214227@gmail.com (J.Y.W.); maggie06172002@hotmail.com (C.Y.C.); 1tchang@nchu.edu.tw (C.L.T.C.)

2 Department of Veterinary Medicine, National Pingtung University of Science and Technology, 91201 Pingtung, Taiwan; cflin2283@mail.npust.edu.tw (C.F.L.)

Cheng-Ying Yang and Jhih-Ying Wong contributed equally.

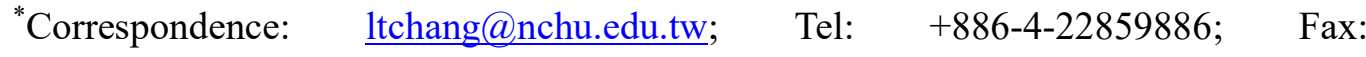
886-4-22862073

Simply Summary: Translation of new cancer treatments between pets and human were noticed in comparative oncological investigation. The current study aims at evaluating a polyacetylenic glucoside purified from an edible herb, Bidens pilosa, to present its anti-angiogenic effects. We innovatively find this polyacetylenic glucoside, cytopiloyne, shows anti-angiogenic effect on different in vitro assays and various in vivo animal models under hypoxia. Based on results of this study, cytopiloyne will be a prospective herb angiogenesis inhibitor candidate to control animal or human cancer formation as adjuvant therapy.

\begin{abstract}
Anti-angiogenesis is a pivotal combination treatment approach in cancer therapy but rare using on companion animals. This study aimed at evaluating the anti-angiogenic effect of a $B$. pilosa sourced polyacetylenic glucoside, cytopiloyne, on various in vitro assays and in vivo models. We provide evidences showing that $\mathrm{CP}$ has anti-angiogenic activities. Firstly, CP inhibited sponge/ Matrigel plug angiogenesis from tumor cells and decreased the survival of tumor cells on hypoxic conditions. Besides, CP declined PKC $\alpha$ protein expression which a protein leads to the growth and spread of tumors under hypoxia. Secondly, inhibitory effects of CP on endothelial angiogenesis were confirmed by chick chorioallantoic membrane assay, tube formation of SVEC4-10 cells and Matrigel plug assay. A dose-dependent CP treatment inhibited 4T1 cells proliferation under hypoxia and migration. It also suppresses VEGF transcription under hypoxia. Finally, we found that CP decreased
\end{abstract}


PDIA4, a novel regulator of cancer growth, expression in endothelial cells. This effect was confirmed by PDIA4 knockout mice with reduced angiogenesis in Matrigel plug assay. Taken together, these results suggest that $\mathrm{CP}$ might act as a promising anti-angiogenic herbal agent candidate to be used in animal hypervascularized cancer of veterinary medicine or in combination to control human cancer as adjuvant therapy.

Keywords: angiogenesis, Bidens pilosa, cancer, hypoxia, PDIA4, VEGF

\section{Introduction}

Translation of cancer therapeutic strategy between pets and humans became an important target on comparative oncological investigations [1]. A web information (Cancer in Dogs and Cats; Pet Care, March 10, 2020; https://www.prudentpet.com/blog/cancer-dogs-and-cats/) demonstrated that prevalence and mortality of cancer on pets. With one in five cats were diagnosed with cancer. Cancer is often more common in dogs than cats. 50\% of dogs over ten years of age develop cancer. Cancer is the leading cause of death in dogs and cats, mortality of cancer dogs and cats were about $47 \%$ and $32 \%$, respectively. As for treatments, common treatment methods include surgery, chemotherapy, and radiation therapy. Anti-angiogenesis is a pivotal combination treatment approaches in cancer therapy but rare using on companion animals. Current methods using anti-vascular endothelial growth factor (VEGF) antibodies or inhibitors targeting VEGF receptors after surgeon on cancer patients [2]. Due to their low blocking VEGF efficiencies on signaling transfer, toxicity and high risk of adverse effects in clinic [3], a mild and auxiliary method co effectively block cancer angiogenesis during treatment is necessary in veterinary clinic. Recent studies in pet dogs with cancer were undertaken to assist in the evaluation of anti-angiogenic peptide mimetics of thrombospondin 1 (TSP1) [1]. Follow-up study for cooperative activity between cytotoxic chemotherapy and TSP1 anti-angiogenic treatment in dogs with lymphoma has now supported these potential combinational therapies [4].

Based on above-mentioned issues, finding less toxic angiogenesis inhibitors from herbal phytochemicals, such as flavonoids, sulphated carbohydrates, or triterpenoids are being studied $[5,6]$. In advance, phytochemical targeting VEGF and related multifactor as anticancer therapy was also investigated [7-11]. But less active and pure phytocompounds were found, especially worked on hypoxia in vitro and in vivo systems. Many experiments tried to screen functional herbal sources acted on angiogenesis. Among these, members of the B. pilosa (Asteraceae family) are listed as a food staple and herbal medicine by Food and Agriculture Organization of the United Nations and the Taiwan government [12]. It was also used as composition of 
herbal teas in different areas or countries, including native Amazon, Himalaya, Jammu, Kashmir, China, India and Taiwan [13-15]. We previous reported that a polyacetylene glucoside, 2- $\beta$-D-glucopyranosyloxy-1-hydroxytrideca5,7,9,11-tetrayne (named cytopiloyne; CP) manifests anti-diabetic, anti-coccidial, anti-bacterial, anti-candidal and immunomodulatory effects [16-21]. In addition, $B$. pilosa was used as the investigation on anti-cancer [22-24] and anti-angiogenesis [25, 26]. In these related studies on $B$. pilosa demonstrated that polyacetylenes acted as anti-angiogenic agents [25] through activation of CDK inhibitors and caspase-7 [26]. However, the anti-angiogenic mechanism with hypoxia underlying $\mathrm{CP}$ is not clear. Further, over 200 compounds were identified in B. pilosa [12], the using angiogenic models to confirm its anti-angiogenic compounds are deficient, which limits the clinical use in the veterinary medicine.

In this study, we first evaluate the anti-angiogenic effect of $\mathrm{CP}$, on various in vitro systems and in vivo models. Next, using hypoxia system to confirm CP owned anti-angiogenic mechanism through protein kinase $\mathrm{C}$ (PKC) and VEGF modulation. Based on the background, $\mathrm{CP}$ docking and modulate gene protein disulfide isomerase a4 (PDIA4) which acts as a novel regulator of cancer growth. Finally, we also used PDIA4 KO mice verify angiogenesis inhibition effect of VEGF under Matrigel plug assay.

\section{Materials and Methods}

\subsection{Chemicals and Reagents}

Agarose, amiloride, bFGF, dimethyl sulfoxide (DMSO), ethanol, heparin, isopropanol, methanol, MTT assay reagents, SDS, sodium bicarbonate, phosphtase inhibitor cocktail 2, Tris-base and VEGF were purchased from Sigma-Aldrich (St. Louis, MO, USA). RPMI1640 (Cat.31800-022), fetal bovine serum (FBS), $1 \%$ glutaMAX, TRIzol, $1 \mathrm{mM}$ sodium pyruvate, penicillin/streptomycin/glutamine, $1 \%$ nonessential amino acid, trypsin, 5X first-strand buffer and TEMED were obtained from Invitrogen Corp. (Carlsbad, CA, USA). High glucose DMEM (Dulbecco's modified Eagle's medium; $4.5 \mathrm{mg} / \mathrm{mL}$ ) was purchased from Gibco (NY, USA). Monoclonal anti- $\beta$-actin (1:5,000; Abcam, MA, USA), PKC $\alpha$ (1:5,000; Y124, Abcam, MA, USA) and PDIA4 (1:5000; Stressgen, MI, USA) were used. B. pilosa plants were collected from the Farm of Changhua County, Taiwan. CP was prepared to $98 \%$ purity from whole plant of $B$. pilosa as previously described [16]. Briefly, CP was isolated on an RP-18HPLC column by methanol extraction and ethyl acetate partition of whole B. pilosa plants. Structure and purity were confirmed by NMR spectra using a Bruker DMX-500 spectrometer and nuclear magnetic resonance determination, respectively. 


\subsection{Cell Culture}

Murine 4T1 mammary carcinoma cells were obtained from American Type Culture Collection (ATCC, Manassas, VA, USA) and were cultured in RPMI 1640 medium supplemented with 10\% FBS, 1\% non-essential amino acids (NEAA), 1\% glutaMAX, $1 \mathrm{mM}$ sodium pyruvate, $1 \%$ nonessential amino acid and $1 \%$ penicillin/streptomycin/glutamine.

SVEC4-10 cells is an endothelial cell line derived by SV40 (strain 4A) transformation of endothelial cells from axillary lymph node vessels; these fully transformed small vessel murine immortal endothelial cells, were purchased from BCRC (Bioresource Collection and Research Center, Taiwan). These cells were cultured in DMEM supplemented with $10 \%$ FBS, $4 \mathrm{mM}$ L-glutamine and $1.5 \mathrm{~g} / \mathrm{L}$ sodium bicarbonate.

\subsection{Laboratory Animal}

C 57BL/6J Narl mice were obtained from the National Laboratory Animal Center (NLAC; Taipei, Taiwan). PDIA4 KO mice were provided by Dr. W.C. Yang (Agricultural Biotechnology Research Center, Academia Sinica, Taiwan). Animals were housed in a $12 \mathrm{~h}$ light/dark cycle in controlled temperature $\left(22 \pm 2{ }^{\circ} \mathrm{C}\right)$ and humidity $(55 \pm 10 \%)$ in a specific pathogen-free animal facility. All mice gained ad libitum access to rodent diet (5010, LabDiet, MO, USA) and water for 1 week prior to the study and beyond. All animal experiments were performed according to the guidelines of the Institutional Animal Care and Utilization Committee (IACUC) of National Chung-Hsing University (Taichung, Taiwan)(permit number: 101-83).

\subsection{MTT Assay}

MTT assay was used to determine cell viability of 4T1 cells. Briefly, the cells were grown in the presence of CP at $6 \times 10^{3}$ cells/well in a 96-well plate for $24-48 \mathrm{hr}$. After removing medium, MTT dye at $0.5 \mathrm{mg} / \mathrm{mL}$ was added to each well and incubated at $37^{\circ} \mathrm{C}$. After $4 \mathrm{~h}$, DMSO $(150 \mu \mathrm{L} /$ well $)$ was added to each well and incubated at $37^{\circ} \mathrm{C}$ for additional $1 \mathrm{~h}$. The plate was measured at $570 \mathrm{~nm}$ (signal) and $650 \mathrm{~nm}$ (reference) using a microplate reader (UVM340, Biochrom, UK).

\subsection{The Sponge/Matrigel Angiogenesis Assay}

We used a sponge angiogenesis assay modified from the method described by previous studies $[27,28]$. Matrigel $(500 \mu \mathrm{L})$ was injected subcutaneously in the midventral abdominal region of C57BL/6 mice (10-12 weeks of age) and permitted to solidify. Subsequently (after 20-30 min), mice were anesthesized with ketamine 100 $\mathrm{mg} / \mathrm{kg}$ and xylazine $7.0 \mathrm{mg} / \mathrm{kg}$. The skin overlying the Matrigel plug was gently 
shaved, after which a small $(0.5 \mathrm{~cm})$ nick was made in the skin using a \#15 surgical blade. Using the same blade, a smaller nick was made in the Matrigel plug. A sterilized polyvinyl sponge (appx. $3 \times 2 \times 1.5 \mathrm{~mm}$ ) containing with/without $0.1 \times 10^{6} 4 \mathrm{~T} 1$ cells to induce angiogenesis was introduced through the nick in the Matrigel and advanced to the center of the plug with the help of tweezers. The wound was then closed with a suture. Mice were observed after $24 \mathrm{~h}$ to monitor condition of the wound. Plugs could be recovered for several weeks but typically tumor-induced angiogenesis was measured after 7 and 14 days. Mice were killed after 3-5 min; the Matrigel plug with sponge was removed, separated from the abdominal muscle, fixed in $10 \%$ formalin and stained following sections with H\&E. Light microscopy was used to visualize these sections for blood vessels formation and metastasis potential.

\subsection{Chick chorioallantoic membrane (CAM) assay [29]}

One-day-old fertilized eggs were incubated for 3 days in the water-jacketed incubator $\left(38^{\circ} \mathrm{C}, 85 \%\right.$ humidity). Next, the chick embryos with intact yolks were placed in plastic Petri dishes after cracked and incubated with $0 \mathrm{~mL}$ of RPMI-1640 medium $\left(38^{\circ} \mathrm{C}, 85 \%\right.$ humidity, $3 \%$ of $\left.\mathrm{CO} 2\right)$. After 3 days of incubation, the methylcellulose disk containing with BSA $(0.1 \% 100 \mathrm{nM}), 100 \mathrm{nM}$ VEGF, $100 \mathrm{nM}$ bFGF, $30 \mu \mathrm{g}$ amiloride, $2.5 \mu \mathrm{g}$ and $5 \mu \mathrm{g} \mathrm{CP} / \mathrm{embryo}$ was implanted on the CAMs of the individual embryos. After $48 \mathrm{hr}$ of incubation, CAM of individual embryo was photographed for avascular zones formation analysis. The angiostatic effect was determined and normalized as a percentage of the area of blood vessels under the methylcellulose disks (3-5 eggs per treatment) in relation to the non-treated areas.

\subsection{Mouse Matrigel Plug Assay}

Flanks of C57BL/6 mice (8 weeks of age) were injected subcutaneously $500 \mu \mathrm{L}$ of Matrigel (BD Biosciences, MA, USA) with an ice-cold syringe containing bFGF (100 $\mathrm{ng} / \mathrm{mL})$ and heparin $(50 \mathrm{U} / 500 \mu \mathrm{L})$ with or without $\mathrm{CP}(2.5$ or $5 \mu \mathrm{g})$. After seven days, the skin of the mouse was pulled back to expose the Matrigel plug, which remained intact. The Matrigel plugs were weighted and photographed. To quantitate the formation of functional blood vessels, the amount of hemoglobin $(\mathrm{Hb})$ was measured using the Drabkin hemoglobin assay with Drabkin reagent kit 525 (Sigma, MO, USA) as described previously [30]. Plugs were fixed in 10\% formalin and stained following sections with H\&E. Moreover, same experiment and operation was also completed on PDIA4 knockout mice. Another angiogenic factor VEGF (500 $\mathrm{ng} / \mathrm{mL})$ was used in Matrigel $(500 \mu \mathrm{L})$.

\subsection{Tube Formation Assay [31]}


Matrigel $(160 \mu \mathrm{L})$ was loaded into 48 -well plate at $37^{\circ} \mathrm{C}$ for $1 \mathrm{hr}$ for polymerization. SVEC4-10 endothelial cells $\left(2.5 \times 10^{4}\right.$ cells/ well $)$ were added with serum-free DMEM with/without CP $(5 \mu \mathrm{g} / \mathrm{mL})$ for $24-48 \mathrm{hr}$ pretreatment. Tubes will begin to form within 2-4 hr. The final tube phenomenon will be examined under light microscopy after 6 hr.

\subsection{In Vitro Migration Assay [32]}

4T1 cells in medium containing 10\% FBS were seeded into wells of 24-well plates. After the cells grew to confluence, wounds were made by sterile pipette tips. Cells were washed with PBS and refreshed with medium with/without 10\% FBS and various concentrations of $\mathrm{CP}(1,2.5$ and $5 \mu \mathrm{g} / \mathrm{mL})$. After overnight incubation at $37^{\circ} \mathrm{C}$, the cells were fixed and photographed.

\subsection{Hypoxia Induction and Western Blot}

In vitro, hypoxia is modelled in hypoxic incubators set at low oxygen levels (e.g. 1\%) or by treating cells with a chemical mimetic, such as cobalt chloride $\left(200 \mu \mathrm{M} \mathrm{CoCl}_{2}\right.$, 24-48 hr) [33]. 4T1 cells ( $8 \times 10^{5}$ cells) in medium containing $10 \% \mathrm{FBS}$ with/without CP $(5 \mu \mathrm{g} / \mathrm{mL})$ were seeded into wells of 24 -well plates under incubators of normoxia and hypoxia $\left(1 \% \mathrm{O}_{2}, 5 \% \mathrm{CO}_{2}\right.$ and $\left.94 \% \mathrm{~N}_{2}\right)$ in a humidified environment at $37{ }^{\circ} \mathrm{C}$ for 18-24 hr. For PDIA4 expression of SVEC4-10 endothelial cells after CP (2.5 or 5 $\mu \mathrm{g} / \mathrm{mL}$ ) treatment, the incubation time are 12,24 and $48 \mathrm{hr}$. Total lysates from 4T1 cells were electrophoresed by sodium dodecyl sulfate polyacrylamide gel electrophoresis (SDS-PAGE) and, subsequently, transferred to nitrocellulose membrane (Schleicher and Scheull, Keene, NH, USA), immunoblotted with the antibodies against PKC $\alpha$ (1:5,000; Y124, Abcam, MA, USA) and/or $\beta$-actin (1:5,000; Abcam, MA, USA) and horseradish peroxidase (HRP)-conjugated goat anti-mouse IgG as secondary antibody. After developing with ECL substrate (GE Healthcare, Little Chalfont, UK), the membranes were detected using FluorChem HD2 system (Bio-Techne, Minneapolis, MN, USA). Moreover, the PDIA4 expression between CP and SVEC4-10 endothelial cells under various times (12-48 hr) treatment was also detected by western blot. Immunoblotted with the antibodies against PDIA4 (1:5000; Stressgen, MI, USA) and/or $\beta$-actin (1:5,000; Abcam, MA, USA) were utilized.

\subsection{Reverse Transcription-polymerase Chain Reaction (RT-PCR) [34]}

Total RNA was isolated using the Trizol Reagent (Invitrogen, Carlsbad, CA). RT-PCR was carried out with the Superscript II One-Step RT-PCR system with Taq polymerase (Invitrogen) according to the manufacture's protocol using primer sets 
specific for VEGF (5'-GTACCTCCACCATGCCAAGT-3' and 5'-GCGAGTCTG TGTTTTTGCAG-3'), GAPDH (5'-ACAGTCTTCTGAGTGGCA-3' and 5'-CCCATCACCATCTTCCAG-3'). The PCR products were separated by agarose gel electrophoresis and visualized with ethidium bromide. Relative band intensities were quantified by ImageJ software (NIH, Bethesda, MD).

\subsection{Statistical Analysis}

Data from three independent experiments or more are presented as mean \pm SEM. Two-tailed Student's t test, Kruskal-Wallis test and ANOVA test were used for statistical analysis of differences between Groups according to the data type, and a $\mathrm{P}$ value of less than 0.05 was considered to be statistically significant.

\section{Results}

3.1. In vivo Effects of CP on Tumor-induced Angiogenesis in Sponge/Matrigel Assay There are many murine in vivo tumor models for investigating angiogenesis, especially work on oxygen supply and metastasis $[35,36]$. These tumor dissemination methods include tumor cells injection (subcutaneous, intravenous, intraperitoneal and intrahepatic etc.) and graft transplantation but without direct interaction data between angiogenesis and metastasis. For this reason, we use sponge/Matrigel angiogenesis assay [27] was used to check anti-angiogenic effect of CP on hypoxia condition. We found that blood vessel formation was rare in the part of Matrigel around control sponge without 4T1 cells (Fig. 1A. and 1B.; left panels). Apparent angiogenesis was observed in the H\&E section in matrigel with $4 \mathrm{~T} 1$ cell loaden sponge. Because erythrocytes increased in the new formed blood vessels, redness level was apparent elevated around sponge contained 4T1 cells (Fig. 1A. and 1B.; middle panels). Comparing with 4T1 cells group, redness level of Matrigel around 4T1 cells-loaden sponge were apparently observed in CP-cotreated one because inhibition on angiogenesis (Fig. 1A. and 1B.; right panels). 


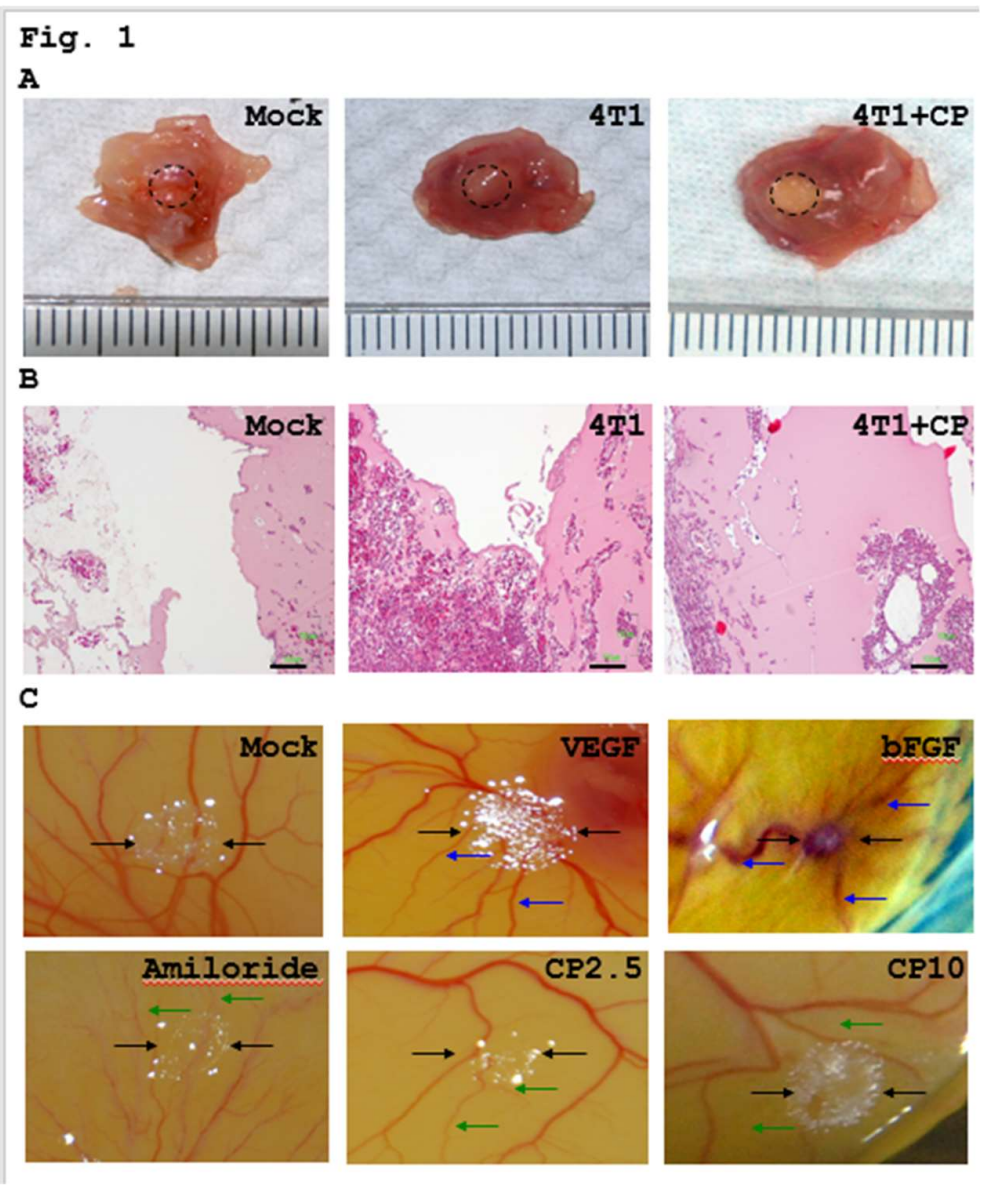

Fig. 1 Anti-angiogenic effects of $\mathrm{CP}$ in sponge/Matrigel Assay (A, B) and chick chorioallantoic membrane (CAM) assay (C). CP inhibited 4T1 cancer cells-induced angiogenesis under sponge/Matrigel assay in C57BL/6 mice. Gross (A) and section with $\mathrm{H} \& \mathrm{E}$ stain (B) photos of removed Matrigel with 4T1 cell loaded sponge were detected after 7-14 days. Dot lines indicated the location of sponge. CP lowered redness in Matrigels (A) and erythrocyte distribution in Matrigel sections (B). CP directly inhibited blood vessel formation in CAM assay (C). After 3 days incubation of fertilized eggs, methylcellulose disk containing with BSA $(0.1 \% 100 \mathrm{nM}), 100 \mathrm{nM}$ VEGF, $100 \mathrm{nM}$ bFGF, $30 \mu \mathrm{g}$ amiloride, $2.5 \mu \mathrm{g}$ and $5 \mu \mathrm{g}$ CP/embryo (CP2.5 and CP5) was implanted on the CAMs of the individual embryos. After $48 \mathrm{hr}$ of incubation, CAM of individual embryo was photographed for avascular zones formation analysis. Black, blue and green arrows indicated the location of methylcellulose disk, new formation of blood vessels and inhibition of angiogenesis, respectively.

\subsection{Influence of CP on Angiogenesis in Chick Chorioallantoic Membrane Assay}

The CAM has served as an in vivo platform for advantages to research and manipulate vascular functions near 60 years. This system has been used for the study of vascular 
development and angiogenesis, especially on tumor growth and metastasis [37]. It can also be advanced studies on respiratory properties, ion transport [34,35], selective vascular occlusion therapies, biocompatibility of engineered materials, drug distribution and toxicology [38-40]. Control CAMs implanted on the empty methylcellulose disks without angiogenic inhibitor did not develop avascular zones as determined by visual examination (Fig. 1C; Mock group). We found that an inhibitor of urokinase plasminogen activator, amiloride, cause a significant reduction of angiogenesis (Fig. 1C; Amiloride group). A larger avascular zone outside of area covered by disk containing this inhibitor was observed. As the positive controls, we used VEGF and bFGF disks, dense areas or increased newly formed vessels were developed (Fig. 1C; VEGF and bFGF groups). In contrast, CP-contained disks apparently showed inhibition of angiogenesis (Fig. 1C; CP2.5 and CP10 groups) under concentrations ( 2.5 and $10 \mu \mathrm{g} /$ disk) lower than amiloride group (30 $\mu \mathrm{g} / \mathrm{disk})$.

\subsection{CP Inhibits Angiogenesis in in vivo Murine Matrigel Plug Assay}

We used matrix gel plug assay, an efficient method, to assess angiogenic and antiangiogenic compounds. First, bFGF was used as positive control. Removed Matrigel plugs were photographed. An increased redness level indicated that angiogenesis was induced by angioenic factor, bFGF (Fig. 2A). More than 30 folds of the content of hemoglobin of the plugs provided a synchronous data on bFGF-induced angiogenesis (Fig. 2B). This significant data was confirmed by higher erythrocytes distribution in Matrigel section with H\&E stain (Fig. 2C). In contrast, CP significantly inhibited angiogenic effect of bFGF in Matrigel plug. The redness level of plugs was decreased, especially on $5 \mu \mathrm{g} \mathrm{CP} / \mathrm{mL}$ plug (Fig. 2A) and confirmed by significant lower content of hemoglobin with almost same as control ones (Fig. 2B). Almost same erythrocytes distributions in plug sections between Mock group and CP groups were observed (Fig. 2C). 


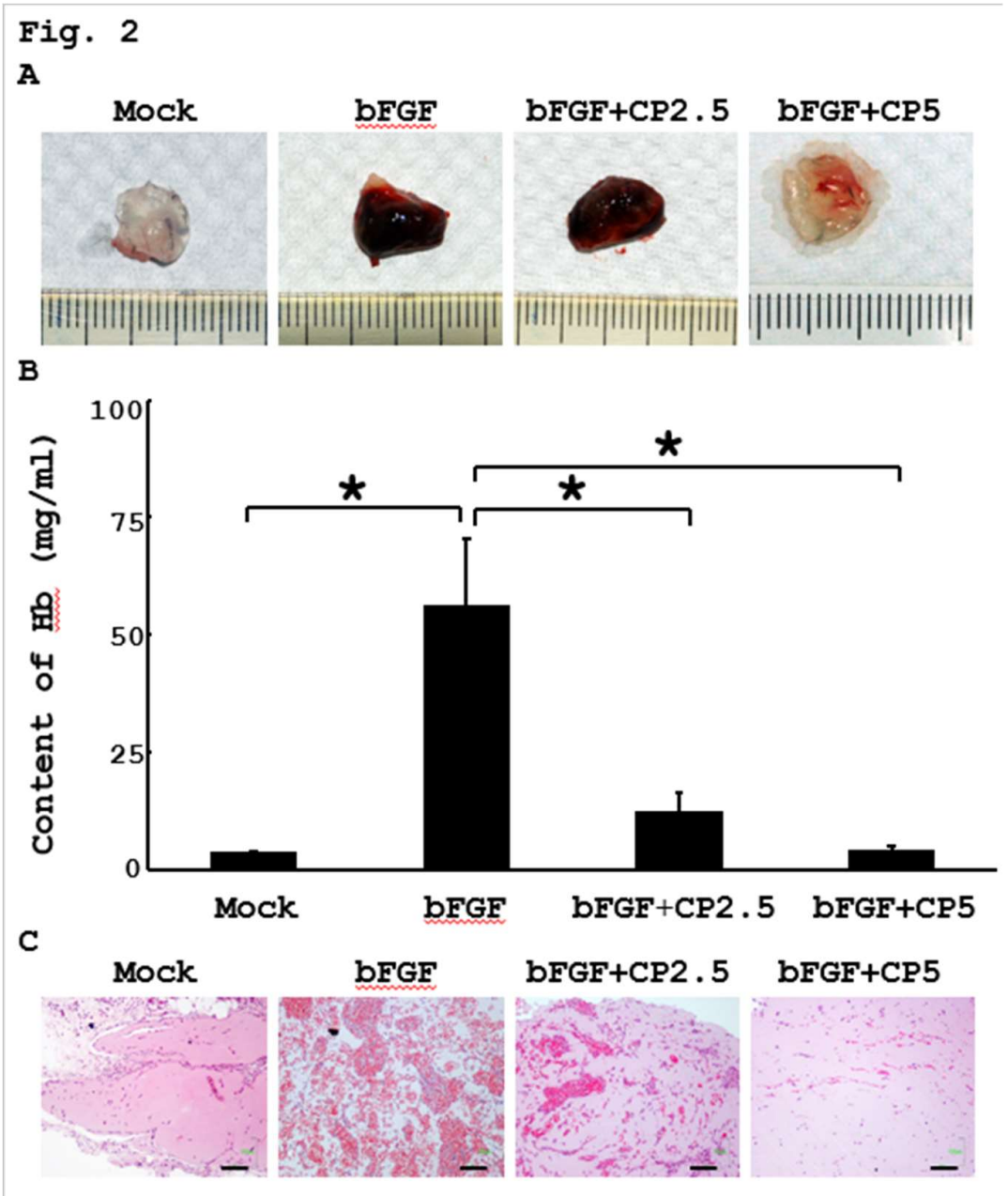

Fig. 2 Inhibitory effect of $\mathrm{CP}$ in bFGF-induced angiogenesis in Matrigel plug assay. Matrigel $(500 \mu \mathrm{L})$ containing bFGF $(100 \mathrm{ng} / \mathrm{mL})$ and heparin $(50 \mathrm{U} / 500 \mu \mathrm{L})$ with or without $\mathrm{CP}(2.5$ or $5 \mu \mathrm{g})$ were subcutaneously injected into $\mathrm{C} 57 \mathrm{BL} / 6$ mice $(8$ weeks of age). After 7 days, the Matrigel plugs were removed for weight and photograph (A). The concentration of hemoglobin $(\mathrm{Hb})$ was measured using the Drabkin hemoglobin assay (B). Sampling part of plugs were fixed and stained with $10 \%$ formalin and H\&E, respectively. These sections were photographed by light microscope observations $(\mathrm{C})$.

\subsection{CP Inhibits the Tube Formation of SVEC4-10 Endothelial Cells}

To estimate the effect of CP on the differentiation of SVEC4-10 cells, we carried out tube formation assay [31]. SVEC4-10 cells were placed on a growth factor-reduced Matrigel-coated plate and were incubated for 24-48 h. As shown in Figure 3A, SVEC4-10 cells on Matrigel formed blood vessel network in the absence of CP, whereas the treatment of CP strongly inhibited the formation of tube-like structure. Moreover, CP did not show toxic effect on SVEC4-10 cells for 24-48 hr (data not 
shown).

\subsection{T1 Cell Viability after CP Treatments under Normoxia and Hypoxia}

As other investigation description, tolerated cancer cells in the hypoxia region will show faster proliferation. But as tumor size increased, the part located away from blood vessels will enhance deterioration on oxygen deficiency and form necrotic zone [41]. This vicious effect on hypoxia will induce advanced angiogenesis [42]. Therefore, screening toxic effect of compounds on cancer cells with angiogenesis under different oxygen levels, normoxia and hypoxia, is a pivotal step. We found that CP $(1$ and $5 \mu \mathrm{g} / \mathrm{mL})$ did not induce any toxic response on 4T1 cells under normoxia by microscopic examination and MTT test (Fig. 3B and 3C). A significant concentration-dependent of increment of dead 4T1 cells after CP treatment under hypoxia was notice (Fig. 3B and 3C). 
Fig. 3

A

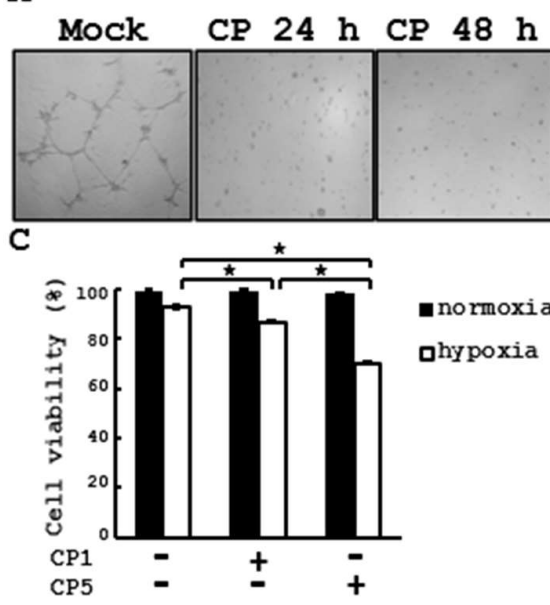

B

Normoxia Hypoxia
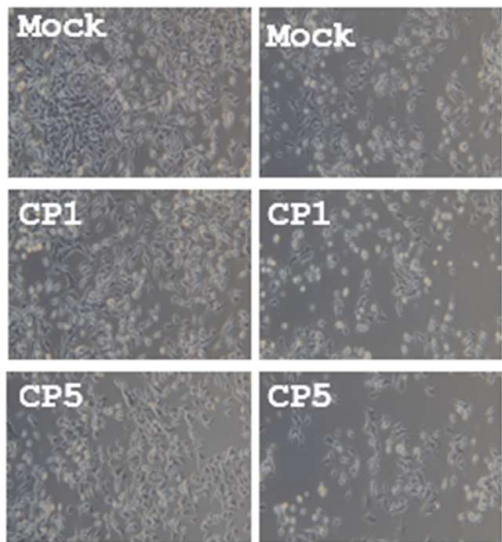

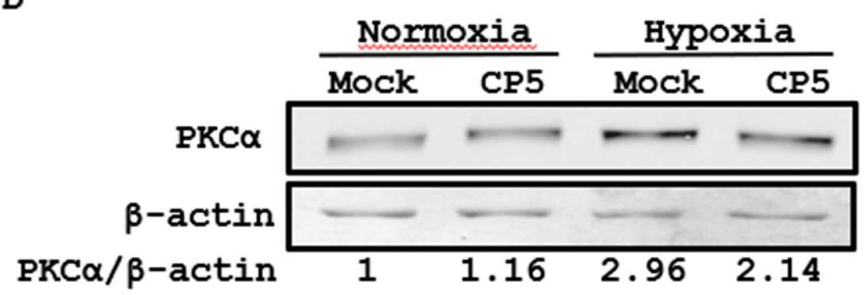

$\mathbf{E}$

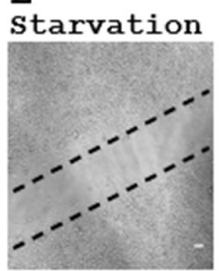

FBS
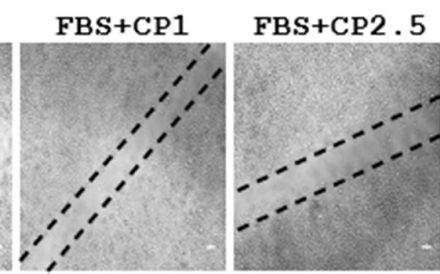

FBS+CP5
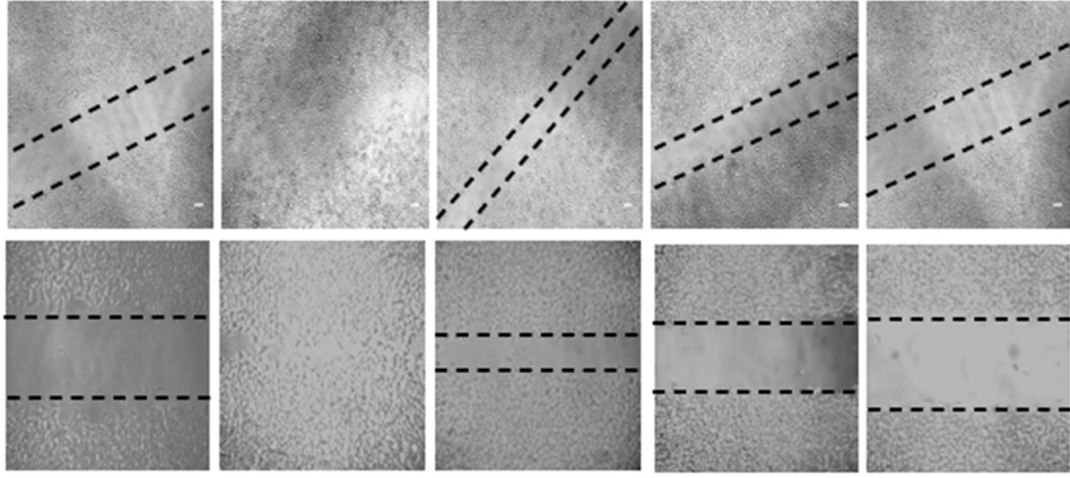

Fig. 3

$\mathbf{F}$

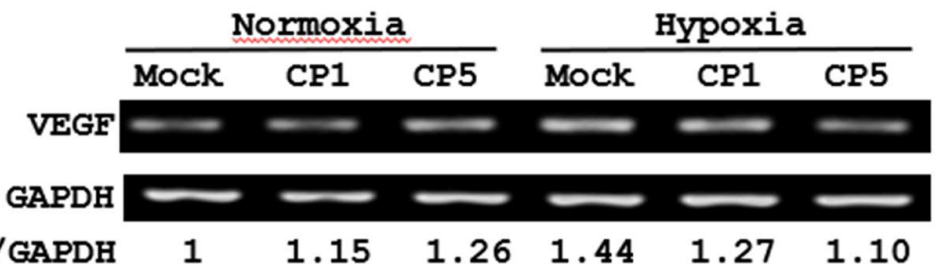

Fig. $3 \mathrm{CP}$ inhibits endothelial cells tube formation, 4T1 cancer cells proliferation and migration under hypoxia state with related mechanisms. SVEC4-10 endothelial cells with/without CP $(5 \mu \mathrm{g} / \mathrm{mL})$ for $24-48 \mathrm{hr}$ pretreatment were added into Matrigel $(160 \mu \mathrm{L} /$ well) coated 48 -well plate. The final tube phenomenon will be 
examined under light microscopy after $6 \mathrm{hr}$ (A). 4T1 cells were incubated with/without $\mathrm{CP}(1$ and $5 \mu \mathrm{g} / \mathrm{mL})$ in a 96 -well plate under normoxia or hypoxia ( $1 \%$ $\mathrm{O}_{2}, 5 \% \mathrm{CO}_{2}$ and $94 \% \mathrm{~N}_{2}$ ) for $24-48 \mathrm{hr}$. These cells were photographed by light microscope observations (B). MTT assay was used to determine cell viability of 4T1 cells (C). Proteins from 4T1 cells lysate under control and CP treatment $(5 \mu \mathrm{g} / \mathrm{mL})$ with normoxia or hypoxia were detected the levels of PKC $\alpha$ and $\beta$-actin by western blot (C). Same cell sources were also analyzed by RT-PCR to detect VEGF transcription levels (F). Except hypoxia state, 4T1 cells migration activity were observed with/without starvation state. A dose-dependent CP treatment (1, 2.5 AND 5 $\mu \mathrm{g} / \mathrm{mL}$ ) showed apparently inhibition of FBS-incubated 4T1 cells migration (E).

\subsection{CP Decreased PKC $\alpha$ Expression VEGF Transcription of $4 T 1$ cells under Hypoxia}

In the early 1980s, PKC was identified as the target of phorbol esters of natural products [43]. Therefore, many dietary phytochemicals were screened for cancer chemoprevention based on PKC pathway related with tumor-promoting activity [44]. $\mathrm{PKC} \alpha$, one of PKC isoforms, which can accelerate tumor cells proliferation/ metastasis and inhibit cancer cells apoptosis [45]. Hypoxia will also induce PKC $\alpha$ expression to promote tumor VEGF production and malignancy [46-48]. We found that $\mathrm{CP}$ did not modify 4T1 cells $\mathrm{PKC} \alpha$ expression on normoxia. But a decreased PKC $\alpha$ level in 4T1 cells with CP treatment was noticed in hypoxia (Fig. 3D). Hypoxia can significantly increase VEGF transcription and production [49]. We used RT-PCR confirmed that 4T1 cells under dose-dependent CP treatment showed lower VEGF transcription under hypoxia, but not normoxia (Fig. 4F).

\subsection{Inhibition of $4 T 1$ Cells Migration by $C P$}

Apart from oxygen deficiency, fast growing tumor presented nutrition demands. Therefore, FBS enhanced 4T1 cells migration by overcome starvation [32] (Fig. 3E). A dose-dependent CP treatment showed apparently inhibition of FBS-incubated 4T1 cells migration (Fig. 3E).

\subsection{CP Decreased PDIA4 Expression of SVEC4-10 Endothelial cells}

Abnormal PDIA4 expression combined endoplasmic reticulum stress is related with a self-protection to various diseases, including angiogenesis related to survival and progression of different cancer types [50-52]. A dose- and time-dependent CP treatment on SVEC4-10 endothelial cells will apparently decrease 30-70\% PDIA4 expression by western blot detection (Fig. 4A).

\subsection{Angiogenesis in in vivo Murine Matrigel Plug Assay on PDIA4 Knockout Mice}


Previous study indicated that PDIA4 is not an essential protein because mice with PDIA4 knockout survive without obvious phenotypes [51]. But no investigation worked on the relationship among angiogenesis, angiogenic factor and PDIA4. VEGF can also induce angiogenesis (Fig. 4B and 4C) which is same as our data in this study of bFGF-induced angiogenesis (Fig. 2) in in Matrigel plug in C57BL/6 mice.

An increased redness level in Matrigel plug indicated that angiogenesis was induced by angioenic factor, VEGF (Fig. 4B). About 5 folds of the content of hemoglobin of the plugs provided a synchronous data on VEGF-induced angiogenesis (Fig. 4C). The VEGF-induced angiogenesis in Matrigel plug on PDIA4 KO mice were significantly decreased (Fig. 4B and 4C).

\section{Fig. 4}

A

CP5 CP2.5

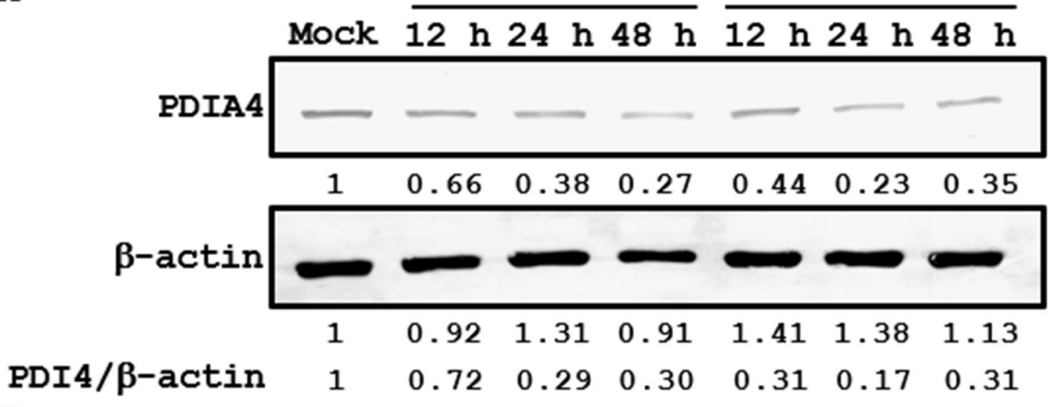

B

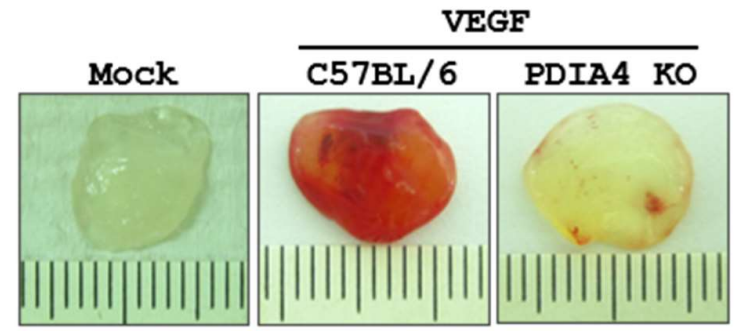

C

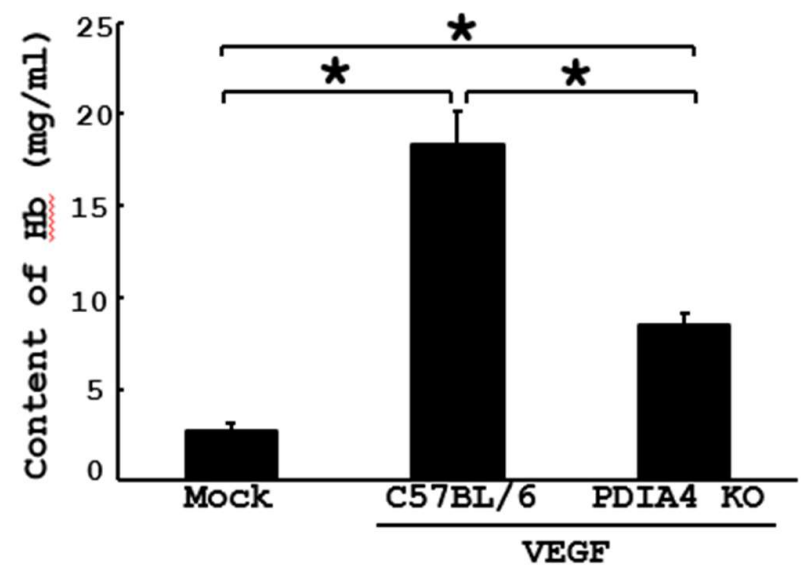

Fig.4 CP inhibits PDIA4 expression in endothelial cells and significant lower angiogenesis in PDIA4 knockout mice. $\mathrm{CP}(2.5 、 5 \mu \mathrm{g} / \mathrm{mL})$ decreased PDIA4 
expression of SVEC4-10 endothelial cells under various time treatment (12-48 hr). PDIA4 expression from these cell lysates were analyzed by western blot (A). Matrigel $(500 \mu \mathrm{L})$ containing VEGF $(500 \mathrm{ng} / \mathrm{mL})$ and heparin $(50 \mathrm{U} / 500 \mu \mathrm{L})$ were subcutaneously injected into PDIA4 knockout mice ( 8 weeks of age). After 7 days, the Matrigel plugs were removed for weight and photograph (B). The concentration of hemoglobin $(\mathrm{Hb})$ was measured using the Drabkin hemoglobin assay $(\mathrm{C})$.

\section{Discussion}

Arthur T. Hertig first name the term angiogenesis in 1935 [53]. Judah Folkman found a revolutionary novel way to consider about cancer and advanced therapy on tumor angiogenesis more than 40 years [54-57]. Based on anti-angiogenic mechanism worked on blocking nutrition and oxygen supply to tumors, more than 10 angiogenesis inhibitors were discover from 1980 to 2005 [57]. After that phytochemicals targeting angiogenic factor and other related inflammatory pathway (eg. upstream PKC activate a distinct set of transcription factors, including NF- $\kappa \mathrm{B}$ ) were screened for cancer prevention and adjuvant therapy [7, 44, 58]. There are many consistencies on tumor types and progression between bet animals and human. Therefore, translational drug development studies became an optimal choice on integrated approach to link the pet dog with cancer and conventional preclinical models (mouse, research-bred dog and non-human primate) and the human clinical trial [1]. Tolerated cancer cells in the hypoxia region will show faster proliferation. But as tumor size increased, the part located away from blood vessels will enhance deterioration on oxygen deficiency and form necrotic zone [41]. This vicious effect on hypoxia will induce advanced angiogenesis [42]. Here, we report a study on a polyacetylene glucoside, cytopiloyne (CP), purified from an edible herbal medicine $B$. pilosa in inhibiting angiogenesis targeting hypoxia through VEGF and PDIA4 suppression through various in vitro and in vivo angiogenic models. Amazingly, our data revealed that CP can inhibit angiogenesis in different animal models researched on angiogenesis (Fig. 1 and 2). In line with the in vivo reduced angiogenesis data induced by CP treatments, CP inhibited mouse 4T1 mammary carcinoma cells proliferation under hypoxia and migration with rich nutrition (FBS) supplement (Fig. $3 \mathrm{~B}, 3 \mathrm{C}$ and $3 \mathrm{E}$ ).

Normal tissues with acute and chronic diseases will present hypoxia under inflammation and toxic response. Cancer cells can tolerate and proliferate in hypoxia but as tumor cells located $>180 \mu \mathrm{m}$ from the blood vessels were observed to become necrotic [59]. Therefore, metastatic tumor cells or new blood vessels formation will prevent the progressive damage on cancer mass. The relationship between hypoxia and angiogenesis on tumor tissue organization were investigated by previous studies. Results of these investigation confirmed that hypoxia-induced angiogenesis will be 
occurred once the tumor size exceeds $1000 \mu \mathrm{m}$ diameter and/or the distance to the nearest blood vessel exceeds $180 \mu \mathrm{m}$ [60]. Direct cancer cells injection or tumor graft transplantation cannot fully provide a mimic animal model link hypoxia, angiogenesis and metastasis. So, we used a cancer cells-loaded sponge/Matrigel assay to confirm that $\mathrm{CP}$ can inhibit 4T1 cells migrate from sponge into Matrigel and form new blood vessel from implanted mice (Fig. 1A and 1B) to overcome oxygen and nutrient deficiency. CAM assay and bovine aortic endothelial cells (BAECs) model are easy and quick ways to screen out drugs or phytochemicals influence angiogenesis. Based on these assays, there are 3 herbs enhanced and 7 herbs significantly inhibited angiogenesis which were screened from 24 traditional Chinese medicines used as curing ischemic heart disease in clinic [61]. Comparing positive angiogenic factors, VEGF and bFGF, CP can direct suppress chick embryo blood vessels development as amiloride, an inhibitor of urokinase plasminogen activator, inhibiting angiogenesis (Fig. 1C). Besides the direct inhibitory effect of angiogenesis of $\mathrm{CP}$, we also check whether or not $\mathrm{CP}$ can lower the angiogenic effect on bFGF stimulation. A dose-dependent $\mathrm{CP}$ treatment significantly curbs bFGF-induced angiogenesis used in vivo murine Matrigel plug assay (Fig. 2). At least 10-30 folds lower concentrations of hemoglobin extract from erythrocytes in plugs were analyzed in CP groups (Fig. 2B). Moreover, the matrix gel plug assay has proven to be a convenient and powerful method to evaluate gene regulation in angiogenesis, angiogenic and antiangiogenic compounds in vivo, and to supplement in vitro tests [62]. As above mention, PDIA4 is gene related with regulating cancer growth [50-52]. Similar as Fig. 2, another angiogenic factor VEGF can induce angiogenesis in Matrigel plug in implanted mice (Fig. 4). Significantly, PDIA4 KO mice did not show VEGF-induced angiogenesis in Matrigel plug (Fig. 4B and 4C). The hemoglobin levels decreased about 5 folds in PDIA4 mice implanted with VEGF plug (Fig. 4C). It meant that PDIA4 is related with angiogenesis on tumor progression.

As other investigation description, polyacetylenes isolated from B. pilosa possess significant anti-angiogenic effects and regulate the expression of cell cycle mediators, p27(Kip1), p21(Cip1), or cyclin E, on human umbilical vein endothelium cells (HUVEC) [25]. Advanced data following this study indicated that a novel polyacetylene, 1,2-dihydroxy-5(E)-tridecene-7,9,11-triyne, structure similar with $\mathrm{CP}$ can promote apoptosis of HUVEC through overexpress death ligand FasL, activate caspase-7 and CDK inhibitors to inhibit angiogenesis [26]. These pilot studies worked on anti-angiogenesis of polyacetylenes from B. pilosa did not provide direct data on angiogenesis animal models and responses of cancer cells under hypoxia. But they suggest that phytocompounds such as polyacetylenes owned potential as candidates for anti-angiogenic therapeutics [26]. In our study, we provided different in vivo data 
to confirm that CP can inhibit angiogenesis and probably suppress metastasis (Fig. 1, and 2). Correlated in vitro data also prove that $\mathrm{CP}$ can slow $4 \mathrm{~T} 1$ cells migration and endothelial cell tube formation (Fig. 3A and 3E). More important, the toxic effect of $\mathrm{CP}$ on $4 \mathrm{~T} 1$ cells only presented in hypoxia (Fig. 3B and 3C). It meant that polyacetylenes with anti-angiogenic effects, especially $\mathrm{CP}$, showed safe characteristic and owned potential in combinational therapy with other cancer treatment. Apart from these in vitro and in vivo data of $\mathrm{CP}$ used to evaluate anti-angiogenic effects, this is the first report to demonstrate that polyacetylene worked on angiogenic factors under hypoxia. First, we checked PKC $\alpha$ expression in 4T1 cell under hypoxia. CP can suppress PKC $\alpha$ expression in 4T1 cells under hypoxia but not nomoxia (Fig. 3D). Because elevated PKC $\alpha$ expression will increase VEGF levels in tumors under hypoxia and enhance malignancy progression [46-48]. Next, we found that higher VEGF transcription in 4T1 cells under hypoxia was decreased by $\mathrm{CP}$ co-incubation (Fig. 3F).

Of note, the anti-angiogenic mode of action of CP needs to be further addressed and is under way. At the outset, the data in this study indicated that $\mathrm{CP}$ will be a safe phytocompound to be used in cancer patient and pet animals, especially on early stage. $\mathrm{CP}$ did not enhance angiogenesis and toxic effect under normoxia (Fig. 3B-D and 3F). Second, the data in previous publications $[16,21,63]$ and this work suggest that $\mathrm{CP}$ owned immune modulatory effects, especially on anti-inflammation. Approximately $15 \%$ of all cancers are linked to inflammation which contributes to the development of neoplasms. Related intracellular signaling mechanisms involved in NF- $\mathrm{BB}$ activation and the induction of iNOS response [64]. Our other investigation found that CP inhibited inflammatory cytokines production by lymphocyte $[16,21]$ and suppressed NF-kB pathway and iNOS activity (data not shown). Usually, anti-inflammatory drugs will be used in cancer patients or pets, but non-steroidal anti-inflammatory drugs (NSAIDS) will raise the risk of cardiovascular incidence and gastrointestinal bleeding, make herbs and spices potentially appealing alternatives [65]. Extract from B. pilosa can improve gastric ulcer [66, 67] and cardiovascular function [68]. Taken together with our earlier publications [16, 21, 63], our data illustrate the applicability of $\mathrm{CP}$ for prophylactic use or combination therapy to control abnormal angiogenesis in progressive tumor development.

\section{Conclusions}

Finding anti-angiogenic drugs and/or alternative herbal drugs is a key and difficult works to overcome. For these reasons, we tried to evaluate the anti-angiogenic effect and related mechanism of CP purified from B. pilosa. We found this polyacetylenic glucoside from a safe and edible herbal medicine can significantly inhibit 
angiogenesis in various animal models (sponge/Matrigel angiogenesis assay, CAM and Matrigel plug assay) and in vitro angiogenic systems (tube formation assay and migration assay). The anti-angiogenic effect of $\mathrm{CP}$ is especially significantly presented under hypoxia state through inhibiting PKC $\alpha$ expression and VEGF expression. We also confirmed that a CP docking gene PDIA4 on a knockout mouse model which inhibit angiogenesis by Matrigel plug assay. Finally, further research screening anti-angiogenic polyacetylenic phytochemicals to achieve clinical usage on human and pet cancer patients will be need for translation medicine investigation,

Author Contributions: Conceptualization, C.L-T.C.; investigation and supervision, C.L-T.C., C.Y.Y., J.Y.W. and C.Y.C.; writing-review and editing, C.L-T.C., C.F.L., and C.L.L. All authors have read and agreed to the published version of the manuscript.

Funding: Ministry of Science and Technology of Taiwan (MOST 101-2313-B-005-019-, 102-2313-B-005-013-MY3 and 107-2321-B-001-033-) and Council of Agriculture of Taiwan (107AS-2.3.1-LI-L1) grants supported this work.

\section{Acknowledgments:}

The authors thank all the members of CLTC laboratories for their technical assistance and editing the manuscript. PDIA4 KO mice were generously provided by Dr. W.C. Yang (Agricultural Biotechnology Research Center, Academia Sinica, Taiwan).

Conflicts of Interest: The authors have no conflicts of interest with any financial organization regarding the material discussed in the manuscript.

\section{References}

1. Paoloni M, Khanna C. Translation of new cancer treatments from pet dogs to humans. Nat. Rev. Cancer 2008, 8, 147-156.

2. Kristensen TB, Knutsson ML, Wehland M, Laursen BE, Grimm D, Warnke E, et al. Anti-vascular endothelial growth factor therapy in breast cancer. Int. J. Mol. Sci. 2014, 15, 23024-23041.

3. Mikirova NA, Casciari JJ, Riordan NH. Ascorbate inhibition of angiogenesis in aortic rings ex vivo and subcutaneous Matrigel plugs in vivo. J. Angiogenes Res. 2010, 2, 2.

4. Rusk A, Cozzi E, Stebbins M, Vail D, Graham J, Valli V, et al. Cooperative activity of cytotoxic chemotherapy with antiangiogenic thrombospondin-I peptides, ABT-526 in pet dogs with relapsed lymphoma. Clin. Cancer Res. 
2006, 12, 7456-7464.

5. Singh RP, Agarwal R. Tumor angiogenesis: a potential target in cancer control by phytochemicals. Curr. Cancer Drug Targets 2003, 3, 205-217.

6. Sagar SM, Yance D, Wong RK. Natural health products that inhibit angiogenesis: a potential source for investigational new agents to treat cancer-Part 1. Curr. Oncol. 2006, 13, 14-26.

7. Parveen A, Subedi L, Kim HW, Khan Z, Zahra Z, Farooqi MQ, et al. Phytochemicals Targeting VEGF and VEGF-Related Multifactors as Anticancer Therapy. J. Clin.l Med. 2019, 8, 350.

8. Wan L, Zhao Y, Zhang Q, Gao G, Zhang S, Gao Y, et al. Alkaloid extract of Corydalis yanhusuo inhibits angiogenesis via targeting vascular endothelial growth factor receptor signaling. BMC Complement Altern. Med. 2019, 19, 359.

9. Kwon OS, Jeong MS, Kim B, Kim SH. Antiangiogenic Effect of Ethanol Extract of Vigna angularis via Inhibition of Phosphorylation of VEGFR2, Erk, and Akt. Evid. Based Complementary Altern. Med. 2015, 2015, 371368.

10. Zou G, Zhang X, Wang L, Li X, Xie T, Zhao J, et al. Herb-sourced emodin inhibits angiogenesis of breast cancer by targeting VEGFA transcription. Theranostics 2020, 10, 6839-6853.

11. Pratheeshkumar P, Budhraja A, Son YO, Wang X, Zhang Z, Ding S, et al. Quercetin inhibits angiogenesis mediated human prostate tumor growth by targeting VEGFR- 2 regulated AKT/mTOR/P70S6K signaling pathways. PLoS One 2012, 7, e47516.

12. Bartolome AP, Villasenor IM, Yang WC. Bidens pilosa L. (Asteraceae): Botanical Properties, Traditional Uses, Phytochemistry, and Pharmacology. Evid. Based Complementary Altern. Med. 2013, 2013, 340215.

13. Bhatt K. C. NS, Anjula Pandey. 'Ladakhi tea' Bidens pilosa L. (Asteraceae): a cultivated species in the cold desert of Ladakh Himalaya, India. Genet. Resour. Crop Evol. 2009, 56, 879-882.

14. Chin HW, Lin CC, Tang KS. The hepatoprotective effects of Taiwan folk medicine ham-hong-chho in rats. Am. J. Chin. Med. 1996, 24, 231-240.

15. Shyh-Shyun Huang T-YC, Jeng-Shyan Deng, Li-Heng Pao, Yung-Chi Cheng and Jung Chao. An Ethnobotanical Study on Qīng- Căo-Chá Tea in Taiwan. Front. Pharmacol. 2020, 11, Article 931.

16. Chang CL, Chang SL, Lee YM, Chiang YM, Chuang DY, Kuo HK, et al. Cytopiloyne, a polyacetylenic glucoside, prevents type 1 diabetes in nonobese diabetic mice. J. Immunol. 2007, 178, 6984-6993.

17. Yang WC, Yang CY, Liang YC, Yang CW, Li WQ, Chung CY, et al. 
Anti-coccidial properties and mechanisms of an edible herb, Bidens pilosa, and its active compounds for coccidiosis. Scientific reports 2019, 9, 2896.

18. Chang CL, Liu HY, Kuo TF, Hsu YJ, Shen MY, Pan CY, et al. Antidiabetic effect and mode of action of cytopiloyne. Evid. Based Complementary Altern. Med. 2013, 2013, 685642.

19. Chung CY, Yang WC, Liang CL, Liu HY, Lai SK, Chang CL. Data on the effect of Cytopiloyne against Listeria monocytogenes infection in mice. Data in brief 2016, 7, 995-998.

20. Chung CY, Yang WC, Liang CL, Liu HY, Lai SK, Chang CL. Cytopiloyne, a polyacetylenic glucoside from Bidens pilosa, acts as a novel anticandidal agent via regulation of macrophages. J. Ethnopharmacol. 2016, 184, 72-80.

21. Chiang YM, Chang CL, Chang SL, Yang WC, Shyur LF. Cytopiloyne, a novel polyacetylenic glucoside from Bidens pilosa, functions as a $\mathrm{T}$ helper cell modulator. J. Ethnopharmacol. 2007, 110, 532-538.

22. Sundararajan P, Dey A, Smith A, Doss AG, Rajappan M, Natarajan S. Studies of anticancer and antipyretic activity of Bidens pilosa whole plant. Afr. Health Sci. 2006, 6, 27-30.

23. Kviecinski MR, Felipe KB, Schoenfelder T, de Lemos Wiese LP, Rossi MH, Goncalez E, et al. Study of the antitumor potential of Bidens pilosa (Asteraceae) used in Brazilian folk medicine. J. Ethnopharmacol. 2008, 117, 69-75.

24. Kumari P, Misra K, Sisodia BS, Faridi U, Srivastava S, Luqman S, et al. A promising anticancer and antimalarial component from the leaves of Bidens pilosa. Planta Med. 2009, 75, 59-61.

25. Wu LW, Chiang YM, Chuang HC, Wang SY, Yang GW, Chen YH, et al. Polyacetylenes function as anti-angiogenic agents. Pharm. Res. 2004, 21, 2112-2119.

26. Wu LW, Chiang YM, Chuang HC, Lo CP, Yang KY, Wang SY, et al. A novel polyacetylene significantly inhibits angiogenesis and promotes apoptosis in human endothelial cells through activation of the CDK inhibitors and caspase-7. Planta Med. 2007, 73, 655-661.

27. Akhtar N, Dickerson EB, Auerbach R. The sponge/Matrigel angiogenesis assay. Angiogenesis 2002, 5, 75-80.

28. McClelland MR, Carskadon SL, Zhao L, White ES, Beer DG, Orringer MB, et al. Diversity of the angiogenic phenotype in non-small cell lung cancer. Am. J. Respir. Cell Mol. Biol. 2007, 36, 343-350.

29. Swiercz R, Skrzypczak-Jankun E, Merrell MM, Selman SH, Jankun J. Angiostatic activity of synthetic inhibitors of urokinase type plasminogen 
activator. Oncol. Rep. 1999, 6, 523-526.

30. Moore GL, Ledford ME, Merydith A. A micromodification of the Drabkin hemoglobin assay for measuring plasma hemoglobin in the range of 5 to 2000 mg/dl. Biochem. Med. 1981, 26, 167-173.

31. DeCicco-Skinner KL, Henry GH, Cataisson C, Tabib T, Gwilliam JC, Watson NJ, et al. Endothelial cell tube formation assay for the in vitro study of angiogenesis. J. Vis. Exp. 2014, 91, e51312.

32. Shan D, Chen L, Njardarson JT, Gaul C, Ma X, Danishefsky SJ, et al. Synthetic analogues of migrastatin that inhibit mammary tumor metastasis in mice. Proc. Natl. Acad. Sci. U S A 2005, 102, 3772-3776.

33. Harrison H, Pegg HJ, Thompson J, Bates C, Shore P. HIF1-alpha expressing cells induce a hypoxic-like response in neighbouring cancer cells. $B M C$ Cancer 2018, 18, 674.

34. Venkatesha S, Hanai J, Seth P, Karumanchi SA, Sukhatme VP. Lipocalin 2 antagonizes the proangiogenic action of ras in transformed cells. Mol. Cancer Res. 2006, 4, 821-829.

35. Yang S, Zhang JJ, Huang XY. Mouse models for tumor metastasis. Methods Mol. Biol. 2012, 928, 221-228.

36. Xiong G, Stewart RL, Chen J, Gao T, Scott TL, Samayoa LM, et al. Collagen prolyl 4-hydroxylase 1 is essential for HIF-1alpha stabilization and TNBC chemoresistance. Nat. Commun. 2018, 9, 4456.

37. Weiss A, van Beijnum JR, Bonvin D, Jichlinski P, Dyson PJ, Griffioen AW, et al. Low-dose angiostatic tyrosine kinase inhibitors improve photodynamic therapy for cancer: lack of vascular normalization. J. Cell. Mol. Med. 2014, 18, 480-491.

38. Grummer R. Animal models in endometriosis research. Hum. Reprod. Update 2006, 12, 641-649.

39. Valdes TI, Kreutzer D, Moussy F. The chick chorioallantoic membrane as a novel in vivo model for the testing of biomaterials. J. Biomed. Mater. Res. 2002, 62, 273-282.

40. Samkoe KS, Clancy AA, Karotki A, Wilson BC, Cramb DT. Complete blood vessel occlusion in the chick chorioallantoic membrane using two-photon excitation photodynamic therapy: implications for treatment of wet age-related macular degeneration. J. Biomed. Opt. 2007, 12, 034025.

41. Mehrabi M, Amini F, Mehrabi S. Active Role of the Necrotic Zone in Desensitization of Hypoxic Macrophages and Regulation of CSC-Fate: A hypothesis. Front. Oncol. 2018, 8, 235.

42. Al Tameemi W, Dale TP, Al-Jumaily RMK, Forsyth NR. Hypoxia-Modified 
Cancer Cell Metabolism. Front. Cell Dev. Biol. 2019, 7, 4.

43. Griner EM, Kazanietz MG. Protein kinase $\mathrm{C}$ and other diacylglycerol effectors in cancer. Nat. Rev. Cancer 2007, 7, 281-294.

44. Surh YJ. Cancer chemoprevention with dietary phytochemicals. Nat. Rev. Cancer 2003, 3, 768-780.

45. Koivunen J, Aaltonen V, Peltonen J. Protein kinase C (PKC) family in cancer progression. Cancer Lett. 2006, 235, 1-10.

46. Lahn M, Paterson BM, Sundell K, Ma D. The role of protein kinase C-alpha (PKC-alpha) in malignancies of the gastrointestinal tract. Eur. J. Cancer 2004, 40, 10-20.

47. Shih SC, Mullen A, Abrams K, Mukhopadhyay D, Claffey KP. Role of protein kinase $\mathrm{C}$ isoforms in phorbol ester-induced vascular endothelial growth factor expression in human glioblastoma cells. J. Biol. Chem. 1999, 274, 15407-15414.

48. Xu H, Czerwinski P, Hortmann M, Sohn HY, Forstermann U, Li H. Protein kinase $\mathrm{C}$ alpha promotes angiogenic activity of human endothelial cells via induction of vascular endothelial growth factor. Cardiovasc. Res. 2008, 78, 349-355.

49. Wang F, Xu P, Xie KC, Chen XF, Li CY, Huang Q. Effects of tumor microenviromental factors on VEGF expression. Biomed. Rep. 2013, 1, 539-544.

50. Wang Z, Zhang H, Cheng Q. PDIA4: The basic characteristics, functions and its potential connection with cancer. Biomed. Pharmacother. 2020, 122, 109688.

51. Kuo TF, Chen TY, Jiang ST, Chen KW, Chiang YM, Hsu YJ, et al. Protein disulfide isomerase a4 acts as a novel regulator of cancer growth through the procaspase pathway. Oncogene 2017, 36, 5484-5496.

52. Tufo G, Jones AW, Wang Z, Hamelin J, Tajeddine N, Esposti DD, et al. The protein disulfide isomerases PDIA4 and PDIA6 mediate resistance to cisplatin-induced cell death in lung adenocarcinoma. Cell Death Differ. 2014, 21, 685-695.

53. AT H. Angiogenesis in the early human chorion and in the primary placenta of the macaque monkey. Contr. Embryol. Carnegie Inst. 1935, 25, 37-81.

54. Folkman J. Anti-angiogenesis: new concept for therapy of solid tumors. Ann. Surg. 1972, 175, 409-416.

55. Folkman J, Klagsbrun M. Angiogenic factors. Science 1987, 235, 442-447.

56. Folkman J, Langer R, Linhardt RJ, Haudenschild C, Taylor S. Angiogenesis inhibition and tumor regression caused by heparin or a heparin fragment in the 
presence of cortisone. Science 1983, 221, 719-725.

57. Ribatti D. Judah Folkman, a pioneer in the study of angiogenesis. Angiogenesis 2008, 11, 3-10.

58. Munir S, Shah AA, Shahid M, Ahmed MS, Shahid A, Rajoka MSR, et al. Anti-angiogenesis Potential of Phytochemicals for the Therapeutic Management of Tumors. Curr. Pharm. Des. 2020, 26, 265-278.

59. Chen L, Endler A, Shibasaki F. Hypoxia and angiogenesis: regulation of hypoxia-inducible factors via novel binding factors. Exp. Mol. Med. 2009, 41, 849-857.

60. Schito L. Bridging angiogenesis and immune evasion in the hypoxic tumor microenvironment. Am. J. Physiol. Regul. Integr. Comp. Physiol. 2018, 315, R1072-R1084.

61. Wang S, Zheng Z, Weng Y, Yu Y, Zhang D, Fan W, et al. Angiogenesis and anti-angiogenesis activity of Chinese medicinal herbal extracts. Life Sci. 2004, 74, 2467-2478.

62. Yuan K, Orcholski ME, Huang NF, de Jesus Perez VA. In Vivo Study of Human Endothelial-Pericyte Interaction Using the Matrix Gel Plug Assay in Mouse. J. Vis .Exp. 2016, 118: e54617.

63. Chiu SC, Tsao SW, Hwang PI, Vanisree S, Chen YA, Yang NS. Differential functional genomic effects of anti-inflammatory phytocompounds on immune signaling. BMC Genom. 2010, 11, 513.

64. Kaefer CM, Milner JA. The role of herbs and spices in cancer prevention. $J$. Nutr. Biochem. 2008, 19, 347-361.

65. Surh YJ, Kundu JK, Na HK, Lee JS. Redox-sensitive transcription factors as prime targets for chemoprevention with anti-inflammatory and antioxidative phytochemicals. $J$. Nutr. 2005, 135, 2993S-3001S.

66. Horiuchi M, Wachi H, Seyama Y. Effects of Bidens pilosa L. var. radiata Scherff on experimental gastric lesion. J. Nat. Med. 2010, 64, 430-435.

67. Tan PV, Dimo T, Dongo E. Effects of methanol, cyclohexane and methylene chloride extracts of Bidens pilosa on various gastric ulcer models in rats. $J$. Ethnopharmacol. 2000, 73, 415-421.

68. Dimo T, Nguelefack TB, Tan PV, Yewah MP, Dongo E, Rakotonirina SV, et al. Possible mechanisms of action of the neutral extract from Bidens pilosa L. leaves on the cardiovascular system of anaesthetized rats. Phytother. Res. 2003, $17,1135-1139$. 